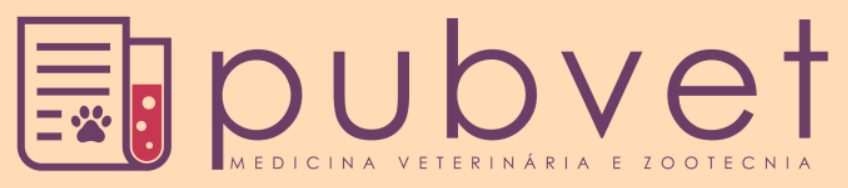

https://doi.org/10.31533/pubvet.v12n8a145.1-8

\title{
Estudo clínico-oftálmico e citológico de felinos domésticos com conjuntivite e mantidos em adensamento populacional
}

\author{
Giovana Patrícia de Oliveira e Souza Anderlini ${ }^{*} \bullet$, Joaquim Evêncio Neto ${ }^{2} \bullet$, Giulliano \\ Aires Anderlini ${ }^{3}{ }^{\bullet}$, Priscilla Nogueira de Melo Omena ${ }^{\bullet}$, Elton Hugo Lima da Silva

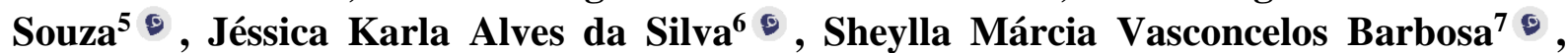 \\ Rinaldo Cavalcante Ferri ${ }^{8}{ }^{\circ}$, Manoel Adrião Gomes Filho ${ }^{\circ}$, Edmilson Ferreira de \\ Oliveira Filho ${ }^{\ominus}$, Fabricio Bezerra de Sá $^{\ominus}$ \\ ${ }^{1}$ Professora do Centro Universitário Cesmac (Marechal Deodoro, Alagoas, Brasil) \\ ${ }^{2}$ Professor da Universidade Federal Rural de Pernambuco, Departamento de Morfologia e Fisiologia Animal (Recife, Pernambuco, Brasil) \\ ${ }^{3}$ Professor do Centro Universitário Cesmac (Marechal Deodoro, Alagoas, Brasil) \\ ${ }^{4}$ Médica Veterinária Autônoma (Maceió, Alagoas, Brasil) \\ ${ }^{5}$ Doutorando da Universidade Federal Rural de Pernambuco (Recife, Pernambuco, Brasil) \\ ${ }^{6}$ Mestranda da Universidade Federal Rural de Pernambuco (Recife, Pernambuco, Brasil) \\ ${ }^{7}$ Residência em Área Profissional de Saúde em Medicina Veterinária da UFRPE (Recife, Pernambuco, Brasil) \\ ${ }^{8}$ Doutor em Biociência Animal pela Universidade Federal Rural de Pernambuco (Recife, Pernambuco, Brasil) \\ ${ }^{9}$ Pós-doutorado na Universidade de Liège, Bélgica \\ *Autor para correspondência, giosouza@msn.com
}

\begin{abstract}
RESUMO. As conjuntivites se propagam facilmente em felinos, especialmente em abrigos e domicílios com elevado número de animais, diante dessa realidade objetivou-se com este estudo fazer uma avaliação oftálmica e citológica em felinos domésticos com conjuntivite e mantidos em adensamento populacional. Para tanto, foram estudados 18 animais da espécie felina, provenientes da rotina de atendimento oftálmico de dois abrigos e um domicilio. Dentre os sinais clínicos, houve predomínio de hiperemia conjuntival, quemose, e secreção mucopurulenta. Associados à conjuntivite, foram atendidos felinos apresentando úlcera dendrítica, simbléfaro e Phthisis bulbi. Na citologia, além das células epiteliais, houve maior frequência de neutrófilos, foram encontradas também inclusões citoplasmáticas morfologicamente compatíveis com Chlamydophila felis e bactérias. O estudo permitiu direcionar o diagnóstico com baixo custo e rapidez, sendo possível instituir terapia tópica e/ou sistêmica aos felinos com conjuntivite, além de oportunizar orientações sobre manejo com o objetivo de minimizar a disseminação das oftalmopatia nos animais mantidos em adensamento populacional.
\end{abstract}

Palavras chave: citologia ocular, oftalmologia felina, superpopulação felina

\section{Ophthalmic clinical and cytological study of domestic cats with conjunctivitis and kept in population density}

\footnotetext{
ABSTRACT. Conjunctivitis spread easily among cats, especially in shelters and homes with large numbers of animals, this reality is objective of this study was to make an ophthalmic and cytological evaluation in cats with conjunctivitis and kept in high population density. For this purpose, 18 animals of the domestic feline, from kind of routine ophthalmic originated from two shelters and one home. Among the clinical signs, there was a predominance of conjunctival hyperemia, chemosis, and purulent secretion. In addition to the signs of conjunctivitis cats presenting ulcer dendítrica, symblepharon and phthisis bulbi were also treated. In the cytology, results showed in addition to epithelial cells, a higher frequency of neutrophils and cytoplasmic inclusions morphologically compatible
} 
with and Chlamydophila felis bacteria. The study allowed direct diagnosis with low cost and speed, making it possible to establish topical and / or systemic therapy for cats with conjunctivitis, as well as create opportunities for management guidelines aimed to minimize the spread of ophthalmopathy in animals kept in high population density.

Keywords: ocular cytology, feline ophthalmology, feline overpopulation

\title{
Estudio clínico oftálmico y citológico de felinos domésticos con conjuntivitis y mantenidos en superpoblacional
}

\begin{abstract}
RESUMEN. Las conjuntivites se propagan fácilmente en felinos, especialmente en abrigos y domicilios con elevado número de animales, frente a esa realidad se objetivó con este estudio hacer una evaluación oftálmica y citológica en felinos domésticos con conjuntivitis y mantenidos en densificación poblacional. Para ello, se estudiaron 18 animales de la especie felina, provenientes de la rutina de atención oftálmica de dos abrigos y un domicilio. Entre los signos clínicos, hubo predominio de hiperemia conjuntival, edema y la secreción mucopurulenta. Asociados a la conjuntivitis, fueron atendidos felinos presentando úlcera dendrítica, simbléfaro y Phthisis bulbi. En la citología, además de las células epiteliales, hubo mayor frecuencia de neutrófilos, se encontraron también inclusiones citoplasmáticas morfológicamente compatibles con Chlamydophila felis y bacterias. El estudio permitió dirigir el diagnóstico con bajo costo y rapidez, siendo posible instituir terapia tópica y / o sistémica a los felinos con conjuntivitis, además de oportunizar orientaciones sobre manejo con el objetivo de minimizar la diseminación de las oftalmopatías en los animales mantenidos en densificación poblacional.
\end{abstract}

Palabras clave: citología ocular, oftalmología felina, superpoblación felina

\section{Introdução}

A conjuntivite é um problema frequente que acomete felinos domésticos e os agentes infecciosos são os principais responsáveis por este quadro (Hillstrom et al., 2012). A exposição da conjuntiva favorece esta condição (Giuliano, 2005) sendo ela o epitélio que recobre a parte exposta da esclera e a superfície interna das pálpebras, suas secreções mucosas protegem a superfície exposta do olho (Burkitt et al., 1994).

A etiologia infecciosa da conjuntivite envolve herpesvirus felino tipo 1 (HVF-1), Chlamydophila felis e Mycoplasma felis (Hartmann et al., 2010), e as enfermidades oculares desencadeadas por estes agentes são comuns em abrigos e domicílios com alto número de felinos adensados (Holst et al., $\underline{2010)}$.

Dentre os sinais clínicos das conjuntivites em felinos destacam-se o edema conjuntival ou quemose, blefarospasmo, hiperemia de conjuntiva e secreção mucosa ou mucopurulenta, todos podendo ser uni ou bilaterais (Hartmann et al., 2010). Outros achados frequentes são o simbléfaro (Barnett, 2006), oftalmia neonatorum (Andrew, 2011), úlceras de córnea com ramificações dendítricas (Schaer, 2006) e sequestro corneano (Gould, 2011).
Através da avaliação oftálmica e de exames complementares, como a citologia conjuntival, é possível direcionar o diagnóstico das oftalmopatias precocemente e intervir no tratamento e manejo de gatos mantidos em adensamento, proporcionando bem-estar e evitando a disseminação de agentes patógenos (Hamor, 2001; La Croix, 2005). Diante da necessidade de estudos oftálmicos em abrigos que possibilitem sugerir diagnósticos com rapidez e custo reduzido é que faz deste trabalho relevante. Para tanto objetivou-se realizar uma avaliação clínico-oftálmica e citológica de felinos domésticos com conjuntivite e mantidos em adensamento populacional.

\section{Material e Métodos}

Foram utilizados 18 felinos sendo 12 machos e 6 fêmeas, todos sem raça definida, não vacinados, com idade variando entre 3 meses e 10 anos, provenientes da rotina de atendimento de um domicílio e dois abrigos. O critério de inclusão utilizado nesta pesquisa, além da sintomatologia ocular uni ou bilateral, foi o adensamento populacional. Como controle foram utilizados seis felinos pertencentes às mesmas condições de adensamento sem sinais clínicos de afecção ocular. 
A idade dos animais foi estimada a partir dos registros locais, tamanho e dentição dos felinos, alocados em seis categorias: 0-3 meses, 4-6 meses, 7-11 meses, 12-72 meses, 72-96 meses e acima de 96 meses conforme Bannasch \& Foley (2005).

Em todas as consultas oftálmicas os pesquisadores deslocaram-se aos locais com o objetivo de minimizar o estresse dos felinos, bem como registrar as condições de adensamento populacional. As informações de cada paciente, assim como a descrição de achados clínicos foram descritas em uma ficha individual.

Os felinos foram contidos manualmente $\mathrm{e}$ submetidos a exame oftálmico iniciado pelo olho esquerdo e posteriormente no contralateral. Durante a manipulação dos pacientes foram usadas luvas de procedimento que foram trocadas após o término de cada avaliação.

Durante o exame oftálmico foi realizada oftalmoscopia direta e testes funcionais como reflexos de ameaça, ofuscamento e reflexo pupilar a luz (RPL) direto e consensual, bem como o Teste Lacrimal de Schirmer (TLS) (Schering-Plough São Paulo, SP, Brasil). A avaliação da integridade da córnea foi realizada com o uso de corantes como rosa bengala (Ophthalmos, São Paulo, SP, Brasil) e fluoresceína (Ophthalmos, São Paulo, SP, Brasil).

Os sinais oftálmicos foram registrados de acordo com a presença de epífora, hiperemia conjuntival, simbléfaro, quemose, secreção ocular mucosa ou mucopurulenta e úlceras corneais e Phthisis bulbi.

Para a avaliação citológica da mucosa conjuntival foi realizada a coleta com auxílio de escova citológica estéril (Adlin Plásticos LTDA, Jaraguá do Sul, SC, Brasil) precedida por colírio anestésico à base de cloridrato de proximetacaína (Anestalcon 0,5\% - Alcon laboratórios do Brasil LTDA, São Paulo, SP, Brasil) no saco conjuntival.

O material foi transferido para uma lâmina de vidro fosca de microscopia óptica e espalhado numa área de aproximadamente $2 \mathrm{~cm}$ de diâmetro. As lâminas foram identificadas seguindo $o$ número de cadastro do animal e a localização, em seguida foram submetidas ao método de coloração rápida Panótico em formulação comercial (Instant-Prov - NewProv, Pinhais, PR, Brasil) e lavadas em água corrente.

Para diferenciar os tipos celulares foram consideradas dois tipos de células nãoinflamatórias (epiteliais e mesenquimatosas) e quatro inflamatórias (Linfócitos, eosinófilos, neutrófilos e macrófagos) segundo Rito (2009).

A avaliação foi feita por microscopia óptica, em objetiva de 40x e, sob imersão, na de100x. Para cada lâmina foram contados dez campos microscópicos e o número de células inflamatórias foi subjetivamente quantificado como ausente, pouco, moderado e muito. A inflamação foi classificada como neutrofílica (cerca de $90 \%$ neutrófilos), linfocítica (cerca de $50 \%$ de linfócitos), ou ainda de caráter misto (neutrófilos e linfócitos). O número de eosinófilos e macrófagos foi notificado. As estruturas encontradas sobre ou dentro das células epiteliais foram identificados como inclusões e/ou grânulos de melanina baseadas na aparência de acordo com literaturas descritas neste trabalho.

Durante a pesquisa foi também realizada venopunção da jugular para coleta de sangue e avaliação leucocitária de todos os felinos.

Em relação ao adensamento, os animais encontravam-se em áreas menores que $1,7 \mathrm{~m} 2$ por gato, que é considerado espaço mínimo permitido para animais em colônias ou abrigos (Damasceno \& Gerano 2013).

Os resultados foram submetidos à análise estatística do tipo descritiva, inseridos em planilhas eletrônicas do tipo Microsoft Excel® Office 2007 (Microsoft Corporation, USA).

\section{Resultados e Discussão}

Dos 18 felinos com conjuntivite $12(66,67 \%)$ eram machos e $6(33,33 \%)$ fêmeas. Em relação à idade, obteve-se neste estudo $2(11,11 \%)$ felinos com idade entre 0 e 3 meses, $9(50 \%)$ entre 4 e 6 meses, $1(5,56 \%)$ entre 7 e 11 meses, $3(16,67 \%)$ entre 12 e 72 meses, $2(11,11 \%)$ entre 72 e 96 meses e $1(5,56 \%)$ com idade acima de 96 meses. Os achados evidenciaram a severidade em animais jovens especialmente por ser esta fase associada ao declínio de anticorpos maternos favorecendo às oftalmopatias segundo Wolf (2004), Barneett (2006), Schaer (2006), Gould (2011) e Hillstrom et al. (2012).

Os exames oftálmicos prolongados frequentemente esgotam tanto o paciente quanto o examinador, para a avaliação de felinos, a melhor contenção é aquela com o menor número de pessoas possível, em certos casos a sedação é utilizada, no entanto há interferência em alguns resultados, sendo preferível a utilização de colírios anestésicos (Gelatt, 2003; Martin, 2010). Em 
detrimento a isso e pelo fato de que estes pacientes ainda seriam submetidos à coleta de sangue, optou-se pela objetividade no exame para identificação de alterações, preferencialmente em córnea, conjuntiva e sistema lacrimal, principais estruturas envolvidas nas conjuntivites infecciosas de felinos.

A conjuntivite foi caracterizada pela presença de epífora, hiperemia conjuntival, quemose e/ou secreção ocular variando entre mucosa e mucopurulenta (Hartmann, 2010); estes sinais foram encontrados isolados ou em conjunto nos 18 animais estudados.

A epífora foi encontrada em 9 felinos (50\%) sendo em $6 \quad(33,33 \%)$ bilateralmente. Esta condição clínica esteve associada, em 3 (16,67\%) animais, ao aumento no TLS e presença de hiperemia conjuntival, caracterizando uma conjuntivite aguda (Hartmann, 2010; Martin, 2010).

$\mathrm{Na}$ citologia, observou-se uma diversidade celular na avaliação citológica das lâminas correspondentes aos dois olhos de cada animal, no entanto, dentre as células inflamatórias encontradas, foi notório o predomínio de neutrófilos. Semelhante à pesquisa de Hillstrom et al. (2012) o número de eosinófilos e macrófagos não foram expressivos em qualquer um dos gatos.

Em $4(22,22 \%)$ felinos avaliados citologicamente foram encontradas células mesenquimatosas classificadas como pouca quantidade. No estudo de Rito (2009) a presença destas células foi relacionada à positividade para o HVF-1. Neste estudo a associação das células mesenquimatosas com sinais clínicos sugestivos de envolvimento por HVF-1 foi visto em um dos felinos que apresentava simbléfaro (Figura 1A).

Verificou-se ainda que a hiperemia conjuntival foi o sinal clínico mais frequente, encontrada em $15(83,33 \%)$ felinos examinados, sendo visto como sinal único em $5(27,78 \%)$ animais; 7 dos 15 animais com hiperemia conjuntival apresentavam secreção mucopurulenta e quemose e, dentre eles, 6 tinham a citologia conjuntival caracterizada como inflamação neutrofílica. Nestes pacientes a avaliação hematológica revelou leucocitose neutrofílica com desvio a esquerda regenerativo leve, que segundo Kociba (2004) caracteriza uma resposta sistêmica a inflamação.

Secreção mucosa, que neste estudo foi encontrada em $3(16,67 \%)$ felinos, se forma quando há menor irritação da conjuntiva sendo misturada com o fluido lacrimal, o que resulta em uma maior viscosidade do último (Stades et al., 1999). Já a secreção mucopurulenta foi encontrada em $11(61,11 \%)$ animais sendo em $7(38,89 \%)$ bilateralmente. Neste estudo não foram evidenciados felinos com ceratoconjuntivite seca.

A conjuntivite bacteriana foi diagnosticada quando as bactérias (cocos, bacilos ou cocobacilos) foram vistas intracelularmente em neutrófilos ou em grande quantidade próximo a neutrófilos e células epiteliais. Em 8 (44,44\%) houve presença de bactérias na citologia, acreditase tratar da própria microbiota bacteriana conjuntival que diante da conjuntivite assume um caráter oportunista (Souza et al., 2010). Observouse ainda predomínio de neutrófilos íntegros, diferenciando de Raskin (2003) que afirmou ser comum degeneração em neutrófilos quando há envolvimento bacteriano.

A conjuntivite e ceratite eosinofílica se manifesta com um infiltrado proliferativo, irregular, branco ou rosa na conjuntiva e/ou córnea. Esta condição pode ser unilateral ou bilateral e não tem relação alguma aparente com o complexo eosinofílico felino. O diagnóstico é baseado na aparência clínica e os resultados da citologia esfoliativa, que revelam eosinófilos, células plasmáticas, linfócitos, mastócitos e macrófagos (Gould, 2011). Em apenas um dos felinos foi evidenciada a presença de poucos eosinófilos na citologia sem sinais clínicos característicos de ceratite eosinofílica.

Os macrófagos foram encontrados nos esfregaços conjuntivais de 4 (22,22\%) felinos estudados. Estas células tem a capacidade de fagocitar bactérias, pequenos parasitas, debris celulares e atuam também como apresentadores de antígenos. Em um dos felinos havia uma inclusão suspeita de $C$. felis e em outro muitas bactérias, justificando assim a presença célula fagocítica (Tozon et al., 2006).

Na citologia conjuntival, a infecção primária e aguda do HVF-1 muitas vezes se observa presença de corpúsculos de inclusão intranucleares, já nos casos crônicos a citologia pode ser frustrante por exibir em sua maioria neutrófilos (Andrew, 2001; Zicola et al., 2009). Apenas em um animal foi verificada uma inclusão sugestiva do HVF-1, esse paciente apresentava epífora, quemose, hiperemia conjuntival, secreção mucopurulenta, espirros e coriza, acreditando-se estar no início da doença. Para Hamor (2001) é raro encontrar quaisquer corpos de inclusão viral nas células epiteliais. 
Um dos felinos apresentava Phthisis bulbi do olho direito (Figura 1B) que é definida como atrofia do bulbo. Esta condição é decorrente de graves processos inflamatórios no olho e tem como sinal evidente a própria atrofia com consequente secreção crônica e desconforto do paciente (Martin, 2010), quadro evidenciado no felino estudado. A citologia conjuntival desse animal foi classificada como inflamatória neutrofílica e foi identificada grande quantidade de bactérias bacilares, inclusive fagocitadas por neutrófilos (Figura 1C). O leucograma revelou leucocitose com neutrofilia e desvio a esquerda regenerativo leve, esse desvio ocorre a medida em que aumenta a liberação de bastonetes que, em geral, é proporcional ao estímulo inflamatório (Kociba, 2004).

Nesta pesquisa ficou evidente a úlcera dendítrica em $2(11,11 \%)$ felinos unilateralmente. Ambos não apresentaram alterações hematológicas, no entanto em um deles havia, além da hiperemia conjuntival e da positividade para o teste de fluoresceína, bem como, quemose, secreção mucopurulenta, vascularização corneana e, durante a avaliação percebeu-se espirros e coriza. As áreas coradas com o colírio Rosa Bengala com aparência dendítrica são patognomônicas para HVF-1, uma vez que elas ressaltam as áreas de necrose epitelial corneal manifestando-se como úlceras (Stades et al., 1999). A citologia deste último foi classificada como inflamação mista, pois estavam presentes neutrófilos e linfócitos, ainda foram identificadas bactérias bacilares e células epiteliais.

Já na citologia do outro felino não foram evidenciados neutrófilos e na avaliação oftálmica foi constatado um leucoma cicatricial. Mesmo diferindo na idade (6 meses e 10 anos) ambos tinham uma lesão linear dendítrica sugerindo infecção por HVF-1. Ficou evidente o quadro oftálmico acentuado no filhote provavelmente por haver infecção bacteriana secundária e por ser esta a faixa etária de declínio de anticorpos maternos (Wolf, 2004; Barneett, 2006; Schaer, 2006; Young \& Prasse, 2009; Gould, 2011; Hillstrom et al., 2012).
A
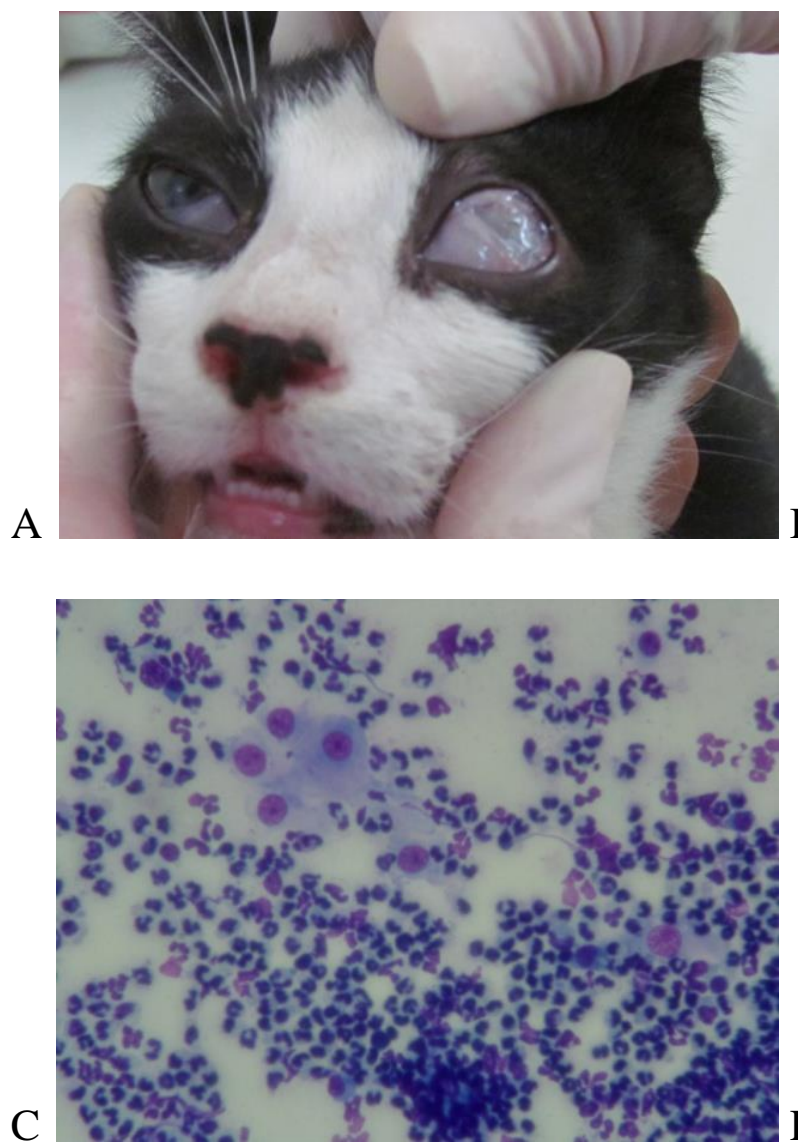
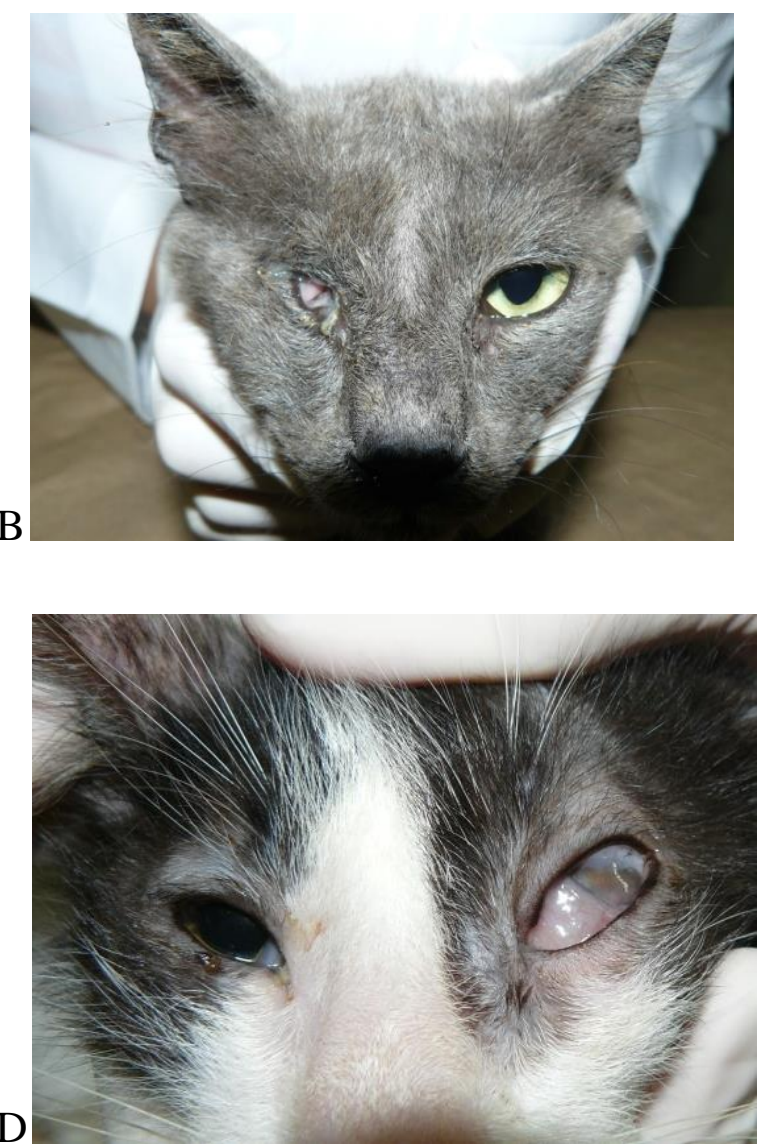

Figura 1. A: Imagem de um dos felinos com simbléfaro. B: Felino com Phthisis bulbi do olho direito exibindo secreção mucopurulenta. C: Citologia conjuntival correspondente ao felino com Phthisis bulbi: presença de muitos neutrófilos (Panótico; 100x). D: Imagem de um dos felinos com simbléfaro. Fonte: Dados da Pesquisa. 
$\mathrm{Na}$ citologia conjuntival de $4 \quad(22,22 \%)$ pacientes foram encontradas inclusões morfologicamente sugestivas de Chlamydophila felis. Este diagnóstico é dado pela presença de corpúsculos de inclusão intracitoplasmática nas células epiteliais durante a fase aguda da doença (Gruffydd-Jones et al., 2009; Turner, 2010). As inclusões podem ser vistas como copúsculos elementares basofílicos e cocóides que se proliferam tornando-se grandes estruturas reticuladas e ligadas à membranas (Raskin, 2003). Na citologia destes animais houve predominância de neutrófilos e em menor quantidade células mononucleadas corroborando com Hamor (2001) e Sykes (2004).

Em $3(16,66 \%)$ felinos foi diagnosticado o simbléfaro (Figura 1A e 1D). Este sinal está associado a infecções ocasionadas pelo HVF-1 que na oftalmologia de felinos é a enfermidade infecciosa mais estudada (Barnett, 2006; Turner, 2010; Gould, 2011). Outra consequência no olho em decorrência do vírus é o sequestro corneano ou mumificação corneana, este sinal foi evidenciado em apenas um felino consultado que provavelmente não estava em primoinfecção por se tratar de um animal de 10 anos, este mesmo animal foi citado anteriormente por apresentar úlcera dendítrica. $\mathrm{O}$ diagnóstico e tratamento das manifestações oculares de felinos portadores de herpesvírus pode ser difícil e frustrante, e as recidivas são comuns em animais infectados (Andrew, 2001).

Em relação aos achados leucocitários, evidenciou-se que $7 \quad(38,89 \%)$ felinos encontravam-se com a leucometria dentro dos valores referenciais. A leucocitose neutrofílica foi encontrada em $11(61,11 \%)$ pacientes, esse achado hematológico é encontrado frequentemente na primeira semana de uma infecção e pode perdurar enquanto houver uma inflamação envolvida (Wolf, 2004).

Apesar da leucocitose não ser um dado a ser considerado nas conjuntivites de felinos adensados, cabe-se uma discussão sobre a sua importância na avaliação sistêmica destes gatos. Em se tratando de bem estar animal, é prudente ressaltar que de acordo com Fam et al. (2010), uma das causas para o aumento na resposta leucocitária é o estresse. $\mathrm{Na}$ oftalmologia felina este fator é preocupante em relação a reagudização do herpesvirus felino tipo 1, onde a doença é frequentemente agravada em gatos estressados (Cohn, 2011). Atrelado a isso, há também o fato de que o felino não é um animal habituado ao confinamento e que o estresse desencadeado nesse tipo de criação pode predispor em longo prazo danos comportamentais importantes como a perda de capacidade de socialização e desenvolvimento da agressividade (Jongman, 2007; Casey \& Bradshaw, 2008; Gouveia et al., 2011).

Para promover o bem-estar dos animais é importante a implantação de áreas mais amplas com esconderijos, visual e de segregação auditiva da população felina, que prevê enriquecimento ambiental através de materiais que fazem barulho com guizos e brinquedos. A ressalva nestes casos é que tais objetos podem aumentar o potencial de transmissão de patógenos, por isso faz-se necessária a separação de grupos com sinais e em tratamento para tais atividades (Cohn, 2011).

\section{Conclusão}

A associação da avaliação oftálmica e a citologia conjuntival é uma rica ferramenta para direcionar o diagnóstico das conjuntivites em felinos mantidos em adensamentos. Sabe-se da necessidade de exames específicos para concluir o diagnóstico das oftalmopatias, entretanto os custos são elevados quando se trata de um número maior de pacientes. Neste estudo, o baixo custo e rapidez do exame, foram fundamentais, permitindo com que o tratamento e a correção do manejo fossem iniciados precocemente.

\section{Referências bibliográficas}

Andrew, S. E. 2001. Ocular manifestations of feline herpesvirus. Journal of feline medicine and surgery, 3, 9-16.

Bannasch, M. J. \& Foley, J. E. 2005. Epidemiologic evaluation of multiple respiratory pathogens in cats in animal shelters. Journal of Feline Medicine and Surgery, 7, 109-119.

Barnett, K. 2006. Diagnostic atlas of veterinary ophthalmology (2a ed., p. 35-45). Elsevier Mosby, London, UK.

Burkitt, H. G., Young, B. \& Heath, J. W. 1994. Wheater - Histologia Funcional (3a ed., p. 376-387). Guanabara Koogan, Rio de Janeiro, BR.

Casey, R. A. \& Bradshaw, J. W. S. 2008. Owner compliance and clinical outcome measures for domestic cats undergoing clinical behavior therapy. Journal of veterinary behavior, 3, 114-124. 
Cohn, L. A. 2011. Feline respiratory disease complex. Veterinary clinics small animal, 4(6), 1273-1289.

Damasceno, J. \& Genaro, G. 2013. Dynamics of the access of captive domestic cats to a feed environmental enrichment item. Applied Animal Behaviour Science, 151, 67-74.

Fam, A. L. P. D., Rocha, R. M. V. M., Pimpão, C. T. \& Cruz, M. A. 2010. Alterações no leucograma de felinos domésticos (Felis catus) decorrentes de estresse agudo e crônico. Revista Acadêmica: Ciências Agrárias e Ambientais, 8(30), 299-306.

Gelatt, K. N. 2003. Manual de oftalmologia veterinária (cap. 1, 594 p.). Manole, São Paulo, BR.

Giuliano, E. A. 2005. Feline ocular emergencies. Clinical techniques in small animal practice, 20, 135-141.

Gould, D. 2011. Feline herpesvirus-1. Ocular manifestations, diagnosis and treatment options. Journal of feline medicine and surgery, 13, 333-346.

Gouveia, K., Magalhães, A. \& Souza, L. 2011. The behaviour of domestic cats in a shelter: Residence time, density and sex ratio. Applied animal behaviour science, 130, 53-59.

Gruffydd-Jones, T., Addie, D., Belák, S., Boucraut-Baralon, C., Egberink, H., Frymus, T., ... horzinek, M. C. 2009. Chlamydophila felis infection. ABCD guidelines on prevention and management. Journal of feline medicine and surgery, 11 (7), 605-609.

Hamor, R. 2001. Techniques for collection and interpretation of tissue samples in ocular disease. Clinical Techniques in Small Animal Practice, 16(1), 17-21.

Hartmann, A. D., Hawlwy, J., Werckenthin, C., Lappin, M. R. \& Hartmann, K. 2010. Detection of bacterial and viral organisms from the conjunctiva of cats with conjunctivitis and upper respiratory tract disease. Journal of feline medicine and surgery, 12(10), 775 - 782.

Hillstrom, A., Tvedten, H., Källberg, M., Hanas, S., Lindhe, A. \& Holst, B. S. 2012. Evaluation of cytologic findings in feline conjunctivitis. Veterinary Clinical Pathology, 41(2),283-290.

Holst, B. S., Hanas, S., Berndtsson, L. T., Hansoon, I., Söderlund, R., Aspán, A., ... Greko, C. 2010. Infectious causes for feline upper respiratory tract disease - a case - control study. Journal of feline medicine and surgery, 12(10), 783-789.

Jongman, E. C. 2007. Adaptation of domestic cats to confinement. Journal of Veterinary Behavior, 2, 193-196.

Kociba, G. J. 2004. Alterações leucocitárias na doença. In: Ettinger, S. J. \& Feldman, E. C. Tratado de medicina interna veterinária (5a ed., cap. 181, p. 1941-1957). Guanabara Koogan, Rio de Janeiro, Brasil.

La Croix, N. C. 2005. Ocular manifestations of systemic disease in cats. Clinical techniques in small animal practice, 20, 121-128.

Martin, C. L. 2010. Ophthalmic disease in veterinary medicine (512 p.). Manson Publishing, London, UK.

Raskin, R. E. 2003. Olhos e estruturas anexas. In: Raskin, R. E. \& Meyer, D. J. Atlas de citologia de cães e gatos (cap. 14, p. 309-323). Roca, São Paulo, Brasil.

Rito, I. Q. S. 2009. Utilização da citologia conjuntival no diagnóstico de doenças oculares.- Universidade Técnica de Lisboa, Lisboa, 100f.

Rochlitz, I. 2000. Recommendations for the housing and care of domestic cats in laboratories. Laboratory Animals, 34, 1-9.

Schaer, M. 2006. Medicina clínica del perro y el gato (p. 48). Masson, Barcelona, ES.

Souza, J. O. T., Angêlo, F. F. \& Homem, L. A. S. 2010. Microbiota bacteriana conjuntival de felinos domésticos (Felis S. catus, Linnaeus, 1758) sadios da cidade de juiz de fora - MG. Revista científica eletrônica de medicina veterinária, Ano VIII, 15.

Stades, F. C., Boevè, M H., Neumann, W. \& Wyman, M. 1999. Fundamentos de oftalmologia veterinária (204 p.). Manole, São Paulo, BR.

Sykes, J. E. 2004. Feline chlamydiosis. Clinical techniques in small animal practice, 20, 129134.

Tozon, N., Suhadolc Scholten, S., Pavlin, D. \& Dovc, A. 2006. Chlamydophila felis infection in cats - clinical cases. Slovenian veterinary research, 43(2), 109-114.

Turner, S. M. 2010. Oftalmologia em pequenos animais (cap. 11, p. 68-75). Elsevier Saunders, Rio de Janeiro, BR.

Wolf, M. A. 2004. Outras doenças virais dos felinos. In: Ettinger, S. J. \& Feldman, E. C. 
Tratado de medicina interna veterinária (5a ed., cap. 92, p. 468-472). Guanabara Koogan, Rio de Janeiro, Brasil.

Young, K. M. \& Prasse, K. W. 2009. Olhos e as estruturas associadas. In: Cowell, R. L., Tyler, R. D., Meinkoth, J. H. \& Denicola, D. B. Diagnóstico citológico e hematológico de cães e gatos (3a ed., cap. 9, p. 149-171). Medvet Ltda, São Paulo, Brasil.

Zicola, A., Saegerman, C., Quatpers, D. \& Thiry, E. 2009. Feline herpesvirus 1 and feline calicivirus infections in a heterogeneous cat population of a rescue shelter. Journal of feline medicine and surgery, 11, 1023-1027.

Recebido: 5 Mai., 2018.

Aprovado: 16 Jun., 2018.

Publicado: 9 Ago., 2018.

Licenciamento: Este artigo é publicado na modalidade Acesso Aberto sob a licença Creative Commons Atribuição 4.0 (CC-BY 4.0), a qual permite uso irrestrito, distribuição, reprodução em qualquer meio, desde que o autor e a fonte sejam devidamente creditados. 